\title{
Bortezomib-enhanced radiosensitization through the suppression of radiation-induced nuclear factor- $k B$ activity in human oral cancer cells
}

\author{
TETSUYA TAMATANI, NATSUMI TAKAMARU, KANAE HARA, MAKOTO KINOUCHI, \\ NOBUYUKI KURIBAYASHI, GO OHE, DAISUKE UCHIDA, KENJI FUJISAWA, \\ HIROKAZU NAGAI and YOUJI MIYAMOTO

\begin{abstract}
Department of Oral Surgery, Subdivision of Molecular Oral Medicine, Division of Integrated Sciences of Translational Research, Institute of Health Biosciences, The University of Tokushima Graduate School, Tokushima 770-8504, Japan
\end{abstract}

Received September 4, 2012; Accepted October 12, 2012

DOI: 10.3892/ijo.2013.1786

\begin{abstract}
Oral cancer cells have a significantly augmented nuclear factor- $\kappa \mathrm{B}(\mathrm{NF}-\kappa \mathrm{B})$ activity and the inhibition of this activity suppresses tumor growth. Bortezomib is a proteasome inhibitor and a drug used for molecular-targeted therapy (targets $N F-\kappa B$ ). In this study, we investigated whether bortezomib would be effective as an inhibitor of proliferation and a radiosensitizer for the treatment of oral cancer. We demonstrate that bortezomib inhibits $\mathrm{NF}-\kappa \mathrm{B}$ activity and cell proliferation. The combined treatment with bortezomib and radiation (RT) suppressed NF- $\kappa \mathrm{B}$ activity and cell growth in vitro and in vivo compared with RT treatment alone. To investigate the mechanisms by which bortezomib suppresses tumor growth, the expression of signaling molecules downstream of $\mathrm{NF}-\kappa \mathrm{B}$ were examined by ELISA. The combined treatment significantly inhibited the radiation-induced production of angiogenic factors and decreased the number of blood vessels in the tumor tissues. Although the expression of anti-apoptotic proteins was upregulated by RT, bortezomib downregulated the RT-induced expression of these proteins. Moreover, the expression of cleaved poly(ADP-ribose) polymerase in vitro and in vivo was enhanced by bortezomib, indicating that bortezomib inhibits tumor growth by inducing apoptosis. This study clearly demonstrates that bortezomib significantly inhibits tumor growth and that the combined treatment with bortezomib and RT results in a significant inhibition of tumor growth. The mechanisms underlying the inhibition of tumor growth by bortezomib include the suppression of angiogenesis and the induction
\end{abstract}

Correspondence to: Dr Tetsuya Tamatani, Department of Oral Surgery, Subdivision of Molecular Oral Medicine, Institute of Health BioSciences, The University of Tokushima Graduate School of Dentistry, 3 Kuramoto-cho, Tokushima 770-8504, Japan

E-mail: ttama@dent.tokushima-u.ac.jp

Key words: nuclear factor- $\kappa \mathrm{B}$, bortezomib, oral cancer of apoptosis. A novel molecular targeting therapy including bortezomib may be effective in the treatment of oral cancer by suppressing $\mathrm{NF}-\kappa \mathrm{B}$ activity.

\section{Introduction}

The 5-year survival rates of advanced stages (stage III and IV) in oral squamous cell carcinoma (OSCC) have not improved. Treatment options are limited and patients with oral cancer frequently fail to respond to standard therapies. However, recent advances in the understanding of the molecular events underlying the initiation, progression and metastatic spread of oral cancer may lead to the discovery of novel therapeutic targets. Despite the fact that concurrent chemoradiation therapy marked an improvement in disease control and survival, the resistance of cancer cells to radiation remains a major therapeutic issue. Based on these considerations, we investigated potential molecular targets for the improvement of treatment in oral cancer.

Nuclear factor $-\kappa \mathrm{B}(\mathrm{NF}-\kappa \mathrm{B})$ represents a family of dimeric transcription factors that are characterized by a 300 -amino acid region, termed the Rel homology domain $(1,2)$. In unstimulated cells, inhibitor of $\mathrm{NF}-\kappa \mathrm{B}(\mathrm{I} \kappa \mathrm{B})$ proteins localize with $\mathrm{NF}-\kappa \mathrm{B}$ dimers in the cytoplasmic compartment by masking the nuclear localization sequences of NF- $\mathrm{KB}$ subunits $(1,2)$. The activation of NF- $\kappa \mathrm{B}$ occurs via various stimuli, such as inflammatory cytokines, or the receptors which initiate the signal transduction cascade leading to activation of the I $\kappa \mathrm{B}$ kinase (IKK) complex (IKK $\alpha, \beta$ and $\gamma$ ) (3-5). Following the activation of IKK, the IKK complex phosphorylates $\mathrm{I} \kappa \mathrm{B}$ at serine residues, which target $\mathrm{I} \kappa \mathrm{B}$ for ubiquitination and degradation by a proteasome-dependent pathway (1-5). Following I $\kappa \mathrm{B}$ degradation, $\mathrm{NF}-\kappa \mathrm{B}$ allows nuclear accumulation that promotes sequence-specific DNA binding and the transcriptional activation of target genes. Akt, which functions downstream of Ras and phosphatidylinositol 3'-kinase (PI3K), control the transcriptional activation through a mechanism that is dependent on IKK function and p65 phosphorylation.

$\mathrm{NF}-\kappa \mathrm{B}$ plays a crucial role in the control of cell growth, differentiation, apoptosis, inflammation, stress response and many 
other physiological processes (3-5). NF- $\kappa \mathrm{B}$ has been reported to selectively enhance the expression of pro-inflammatory cytokines, such as interleukin (IL)-1 $\alpha$, IL-6 and IL-8, as well as the expression of degradative enzymes, such as matrix metalloproteinase (MMP)-9 (6-13), supporting the notion that NF- $\mathrm{B}$ significantly contributes to tumor progression and metastasis in various types of cancer, including OSCC $(14,15)$. Indeed, it has been reported that IL- $1 \alpha$ and IL- 6 are associated with increased the growth of OSCC (13) and that the production of IL-6, IL-8, granulocyte-macrophage colony-stimulating factor (GM-CSF) and vascular endothelial growth factor (VEGF) is associated with the increased angiogenesis and metastasis of SCC (6-13). In addition, it is of particular interest that the expression of IL-1 $\alpha$, IL-6, IL-8, GM-CSF, VEGF and MMP-9 has been shown to be positively regulated by $\mathrm{NF}-\kappa \mathrm{B}(6-13)$. Therefore, the inhibition of $\mathrm{NF}-\kappa \mathrm{B}$ activity may constitute a promising approach in the treatment of oral cancer.

A number of human solid tumor cell lines, multiple myeloma, prostate cancer, leukemia, thyroid cancer and breast cancer, display an increased level of nuclear NF- $\kappa \mathrm{B}$ activity or NF- $\kappa \mathrm{B}$ transcriptional activity (16-23). We have previously shown that human head and neck cancer cells have a significantly enhanced activity of $\mathrm{NF}-\kappa \mathrm{B}$ as compared to their normal counterparts, suggesting that $\mathrm{NF}-\kappa \mathrm{B}$ plays an important role in the development of oral cancer (14). We have also demonstrated that the production of angiogenic and growth factors in response to radiotherapy and chemotherapy is one of the principal mechanisms of inducible radioresistance and chemoresistance in human oral cancers, and that the introduction of super-repressor I $\kappa \mathrm{B} \alpha$ cDNA into human OSCC cells constitutively inhibits the nuclear translocation of $\mathrm{NF}-\kappa \mathrm{B}$, causing a drastic decrease in tumorigenicity, partly as a result of the downregulation of the expression of angiogenic factors and the acquirement of sensitivity to radio- or chemotherapy (15). We have also suggested that $\mathrm{NF}-\kappa \mathrm{B}$ may be an important therapeutic target for the improvement of conventional radiotherapy in OSCC.

A key step in NF- $\kappa \mathrm{B}$ activation involves the $26 \mathrm{~S}$ proteasome. The $26 \mathrm{~S}$ proteasome can be inhibited by a proteasome inhibitor, bortezomib (formally PS-341, or Velcade), which is a dipeptidyl boronic acid that inhibits the $26 \mathrm{~S}$ proteasome (24). Bortezomib has been clinically approved for the treatment of refractory multiple myeloma and mantle cell lymphoma worldwide. A number of clinical trials have investigated the efficacy of bortezomib for the treatment of solid tumors (25-39).

We hypothesized that the inactivation of NF- $\kappa \mathrm{B}$ by bortezomib prior to the treatment of cancer cells with radiation (RT) would sensitize cells to apoptosis, resulting in a more profound cancer cell killing effect. In this study, we investigated our hypothesis by evaluating the effects of bortezomib and the combination of bortezomib and RT on tumor growth, apoptosis, the expression of NF- $\kappa \mathrm{B}$-regulated genes and $\mathrm{NF}-\kappa \mathrm{B}$ activation in oral cancer cells, as well as the mechanisms involved.

\section{Materials and methods}

Cell lines. Three human OSCC cell lines (B88, BHY and HNt) previously established in our laboratory were used in the present study (15). These cells were cultured in DMEM supplemented with $10 \%$ fetal bovine serum(FBS) and $1 \mathrm{X}$ antibiotic/antimycotic (Invitrogen Life Technologies, Carlsbad, CA).
In vitro cell growth assay. Cells $\left(5 \times 10^{3}\right.$ cells per well) were seeded on 96-well plates. Twenty-four hours later, the cells were treated with or without bortezomib, which was supplied by Millennium Pharmaceuticals, Inc. (Cambridge, MA), for $72 \mathrm{~h}$. In parallel, cells were exposed to RT by a Hitachi Medical MBR-1505R2 X-ray generator (Tokyo, Japan). After the $72 \mathrm{~h}$-treatment with or without bortezomib and/or RT, $10 \mu \mathrm{l}$ of $5 \mathrm{mg} / \mathrm{ml}$ 3-(4,5-dimethylthiazol-2-yl)-2,5-diphenyltetrazolium bromide (MTT) (Sigma-Aldrich, St. Louis, MO) were added to each well and the cells were incubated for $4 \mathrm{~h}$. The blue dye absorbed by the cells was dissolved in dimethyl sulfoxide $(100 \mu \mathrm{g} / \mathrm{ml})$ and the absorbance was measured with a spectrophotometer at $540 \mathrm{~nm}$. All assays were run in triplicate.

Luciferase assay. The luciferase assay was performed using the transfected cells. A reporter plasmid $(0.4 \mu \mathrm{g})$ consisting of the $\mathrm{NF}-\kappa \mathrm{B}$ responsive elements (BD Biosciences, San Jose, CA) and the luciferase gene was transfected into 3 cell clones using Effectene transfection reagent (Qiagen, Hilden, Germany). G418-resistant colonies were isolated, the luciferase activity was measured and 3 cell lines were established (B88-luc, BHY-luc and HNt-luc) for use in the following experiments. Cell lysates or tissue extracts were subjected to a luciferase assay using a luciferase assay system (PicaGene, Toyo-Ink, Tokyo, Japan) and a luminometer (LUMAT LB9507; Perkin-Elmer Life and Analytical Sciences). All assays were run in triplicate.

In vivo tumor growth assay. The tumorigenic potential of the cancer cells was assessed by inoculation of the cells into 5- to 6-week-old female athymic BALB/c nude mice (CLEA Japan Inc., Osaka, Japan). Cells $\left(5 \times 10^{6}\right.$ cells) were injected subcutaneously (s.c.) into the backs of 5 mice. When tumors reached $50-100 \mathrm{~mm}^{3}$ in volume, they were either exposed to RT (1.5 Gy/day, 3 times/week), or treated with bortezomib $[0.1 \mathrm{mg} / \mathrm{kg}$, by intravenous (i.v.) injection, 3 times/week] for 2 weeks. Tumors at the inoculation site were examined 3 times/week and the tumor size was measured. Tumor volume was calculated according to the formula: (largest diameter) ${ }^{2} \mathrm{x}$ (smallest diameter) $\mathrm{x} 0.5$. The mice were maintained under pathogen-free conditions and were handled in accordance with the Guidelines for Animal Experimentation of Tokushima University.

Electrophoretic mobility shift assay (EMSA). The probe consisted of NF- $\kappa \mathrm{B}$-specific double-stranded oligonucleotides with the sequence 5'-AGTTGAGGGGACTTTCCCAGGC-3' containing the $\kappa \mathrm{B}$ site from the $\kappa$ light chain enhancer in B cells. Oligonucleotides were end-labeled with $\left[\gamma^{32} \mathrm{P}\right] \mathrm{ATP}$ using polynucleotide kinase and unincorporated $\left[\gamma^{32} \mathrm{P}\right] \mathrm{ATP}$ was removed by Sephadex G-50-packed spin columns (Pharmacia Biotech, Uppsala, Sweden). Nuclear extract preparations and EMSA were carried out as described previously (15).

Western blot analysis. After the cells were either treated with bortezomib or exposed to RT, they were collected and lysed. B88 cells $\left(5 \times 10^{6}\right)$ were subcutaneously inoculated into the backs of nude mice. Tumor-bearing nude mice received an i.v. administration of bortezomib alone $(0.1 \mathrm{mg} / \mathrm{kg} / \mathrm{day}$, 3 days), RT alone (1.5 Gy/day, 3 days), or both in combination. Twenty-four hours after exposure to RT or the i.v. administration of bortezomib, the tumors were excised and the protein 
was extracted. Whole-cell lysates were subjected to electrophoresis on $10 \%$ SDS-polyacrylamide gels, then transferred onto nitrocellulose membranes. The membranes were incubated with the following antibodies: rabbit polyclonal antibodies against Akt, phospho-Akt, IKK $\alpha / \beta$, phospho-IKK $\alpha / \beta$, IкB $\alpha$, phospho-IкB $\alpha$, p65, phospho-p65, FLICE-like inhibitory protein (FLIP) and tubulin were obtained from Cell Signaling Technology, Inc. (Beverly, MA). Mouse monoclonal antibodies against cellular inhibitor of apoptosis (cIAP)1 and X-linked inhibitor of apoptosis protein (XIAP) were obtained from R\&D Systems (Minneapolis, MN), rabbit polyclonal antibody against cIAP2 was from Santa Cruz Biotechnology, Inc. (Santa Cruz, CA), poly(ADP-ribose) polymerase (PARP) was from BD Biosciences and mouse monoclonal antibody against $\beta$-actin was from Sigma-Aldrich. After intervening rinses with PBS(-), the antibody was detected using a chemiluminescence western blotting kit (Amersham, Tokyo, Japan) according to the manufacturer's instructions.

Enzyme-linked immunosorbent assay (ELISA) for quantitative determination of IL- $6, I L-8$ and VEGF. The levels of IL-6, IL-8 and VEGF in the tumor tissues from the untreated control or from the bortezomib-treated or RT-exposed cells were measured by a microtiter-based sandwich enzyme immunoassay system, which is commercially available and specifically estimates the total amount of these factors. After extirpation of tumors, extracted protein samples were subjected to ELISA using immunoassay kits for IL-6, IL-8 and VEGF (BioSource International, Camarillo, CA).

Immunohistochemistry and quantification of blood vessels. The tumors were excised, fixed in formalin and embedded in paraffin. Sections were dewaxed in xylene and rehydrated in graded ethanols according to standard procedures. Antigen retrieval was performed by incubating the sections immersed in $10 \mathrm{mM}$ citric acid in a microwave oven at $100^{\circ} \mathrm{C}$. An anti-factor VIII antibody (DAKO Corporation, Carpinteria, CA) was used as the primary antibody. Negative controls for each material were processed in the same manner, using a non-immunized rabbit IgG (DAKO) instead of the primary antibody. The average number of factor VIII-positive vessels was determined from 3 areas (x200) of the highest vascular density in a section. All histological analyses were carried out using blinded tumor samples.

Localization of p65 protein by fluorescence staining. Cells grown on plain coverslips were fixed in $4 \%$ paraformamide and incubated with rabbit anti-human p65 antibody. The coverslips were then washed and the cells were incubated with fluorescence-conjugated donkey anti-rabbit IgG. The coverslips were mounted and observed under a fluorescence microscope.

RNA isolation and quantitative real-time RT-PCR. When the cells reached subconfluence in culture, they were exposed to RT (15 Gy) with or without bortezomib (5 nM). Forty-eight hours later, total RNA was extracted using TRIzol reagent (Invitrogen Life Technologies). The cDNA was synthesized from $5 \mathrm{mg}$ of total-RNA using an Advantage cDNA PCR kit (Invitrogen Life Technologies). For quantitative real-time PCR, equal aliquots of cDNA were amplified according to the manufacturer's TaqMan universal $(50 \mathrm{ml})$ PCR master mix protocol using RT-PCR ABI PRISM 7000 (Applied Biosystems, Foster City, CA). The primer set and TaqMan probe used for the experiments were included in a TaqMan gene expression assay system (cIAP1; Hs00236911_m1, cIAP2; Hs00154109_m1). The data were normalized using RT-PCR GAPDH primers (Applied Biosystems).

Statistical analysis. Statistical analysis was performed using the Mann-Whitney $U$ test; values of $\mathrm{p}<0.05$ were considered to indicate statistically significant differences.

\section{Results}

Effects of bortezomib on $N F-\kappa B$ activity and tumor growth of oral cancer cells on in vitro and in vivo. To determine whether bortezomib suppresses the proliferation of human oral cancer cells in vitro, we examined the cell proliferation using MTT assay. Bortezomib suppressed the proliferation of the 3 oral cancer cell lines tested (B88, BHY and HNt) in a dose-dependent manner (Fig. 1A). In addition, since the constitutive activation of $\mathrm{NF}-\kappa \mathrm{B}$ has been associated with the growth and survival of cancer cells (16-22), including oral cancer cells, we used a luciferase assay to clarify whether bortezomib can induce the downregulation of $\mathrm{NF}-\kappa \mathrm{B}$ activity (Fig. 1B). Bortezomib suppressed the NF- $\kappa \mathrm{B}$ activity of the 3 cancer cell lines in a dose-dependent manner (Fig. 1B). Subsequently, to investigate whether bortezomib has an antitumor effect against oral cancer cells in vivo, we developed cancer xenografts in nude mice using B88 cells. Bortezomib treatment was initiated after the cancer cell implantation and was continued for up to 15 days, in accordance with the experimental protocol. Animals were sacrificed 16 days after thetumor cell injection and the tumors were excised and weighed. The tumor volume of bortezomib-treated tumors was significantly smaller than that of the untreated controls (Fig. 1C).

Effects of RT on NF- $\kappa B$ binding ability and activity and the expression of signaling pathway molecules. The molecular mechanisms by which RT affects the NF- $\mathrm{KB}$ signaling pathway have not yet been elucidated. Thus, to assess the effects of RT on NF- $\kappa \mathrm{B}$ activity, DNA binding ability and the molecules involved in NF- $\kappa \mathrm{B}$ signaling pathways, we performed luciferase assay, EMSA and western blot analysis. The luciferase assay for $\mathrm{NF}-\kappa \mathrm{B}$ activity and the DNA binding assay for $\mathrm{NF}-\kappa \mathrm{B}$ in nuclear extracts from the cancer cells showed that RT significantly induced $\mathrm{NF}-\kappa \mathrm{B}$ activity in a dose- and a time-dependent manner (Fig. 2A and B). Since the Akt pathway is an upstream signal of NF- $\kappa B$ activation, the altered regulation of the pathways has been suggested to lead to the chemoresistance of oral cancer cells (27). Thus, we investigated whether or not RT phosphorylates Akt, IKK, I $\kappa \mathrm{B} \alpha$ and $\mathrm{p} 65$. We found that RT phosphorylated Akt and IKK $\alpha / \beta$ as well as phosphorylating and degrading I $\kappa \mathrm{B} \alpha$ (Fig. 2C), indicating that the phosphorylation of these proteins may contribute to the chemoresistance of oral cancer cells.

Effects of bortezomib on the $N F-\kappa B$ activity induced by $R T$, the expression of $I \kappa B \alpha$ and localization of 055 in oral cancer cells. 
A
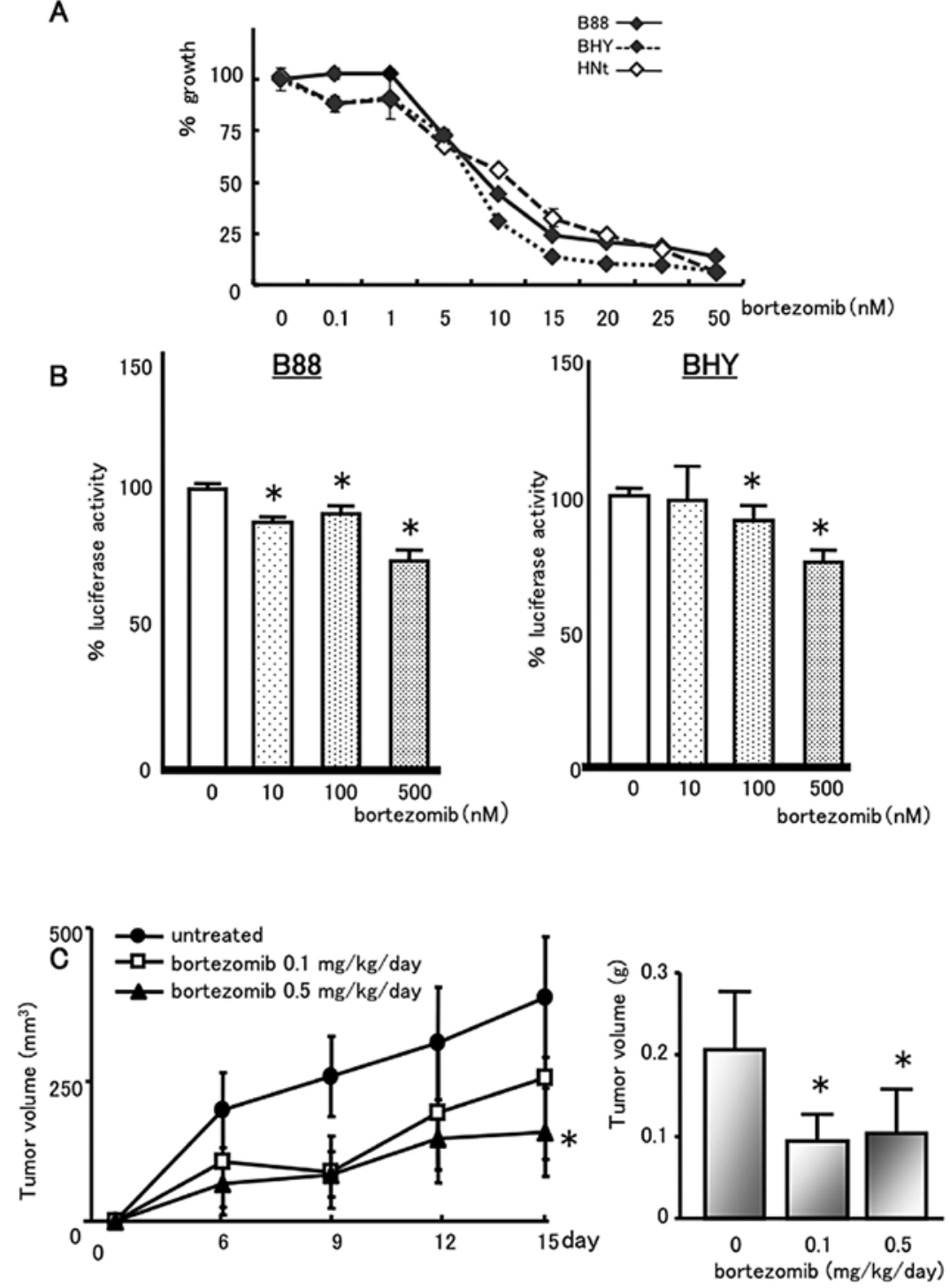

Figure 1. Bortezomib suppressed NF- $\mathrm{kB}$ activity and the proliferation of oral cancer cells. (A) Cells $\left(5 \times 10^{3} \mathrm{cells} /\right.$ well) were seeded in $96-$ well plates. After $24 \mathrm{~h}$, cells were treated with bortezomib. Seventy-two hours later, in vitro cell growth was evaluated by MTT assay as the percentage of growth. (B) The effects of bortezomib on NF-KB activity in B88-luc and BHY-luc cells were investigated by luciferase assay. Cells were seeded in 6-well plates. After $24 \mathrm{~h}$, cells were treated with bortezomib for $5 \mathrm{~h}$. The cells were then subjected to luciferase assay. NF-кB activity was evaluated by luciferase assay as the percentage of luciferase activity. Results are representative of 3 experiments. (C) Effects of bortezomib on in vivo tumor growth. Left panel, B88 cells $\left(5 \times 10^{6}\right)$ were injected s.c. into the backs of nude mice. Bortezomib was administered by i.v. injection ( $0.1 \mathrm{or} 0.5 \mathrm{mg} / \mathrm{kg} /$ day) 3 times/week. Tumors at the inoculation site were monitored 3 times $/$ week and the tumor size was measured. Right panel, after 3 weeks, the mice were sacrificed and the tumors were excised and weighed. "p $<0.05$ versus untreated controls.

To further confirm the effect of bortezomib on NF- $\mathrm{KB}$ activity induced by RT, we analyzed the expression of IкB $\alpha$, the localization of $\mathrm{p} 65$ and NF- $\mathrm{kB}$ activity in cancer cells. The treatment of cells with RT resulted in the degradation of I $\mathrm{B} \alpha$ protein by $35 \%$ compared to the untreated controls (Fig. 3A), whereas bortezomib suppressed the RT-induced I $\mathrm{B} \alpha$ degradation by $62 \%$ compared to the untreated controls. We also performed immunofluorescence staining of p65. As shown in Fig. 3B, RT exposure induced the translocation of the $\mathrm{p} 65$ protein from the cytoplasm to the nucleus in cancer cells. However, bortezomib inhibited the RT-induced nuclear translocation of p65. Finally, treatment with bortezomib followed by exposure to RT significantly suppressed the RT-induced NF- $\mathrm{KB}$ activity in B88 and BHY cells (Fig. 3C). These results indicate that bortezomib inhibits RT-induced NF- $\mathrm{kB}$ activity in oral cancer cells.
Antitumor effects of bortezomib and enhancement of antitumor effects of RT by bortezomib. We examined the effects of bortezomib on the viability of cancer cells (Fig. 4A). To determine whether or not bortezomib enhances the anticancer effect of RT, cell viability was evaluated by MTT assay after $72 \mathrm{~h}$ of treatment with bortezomib and RT in vitro. The exposure of cancer cells to RT after treatment with bortezomib resulted in a synergistic effect on growth suppression. On the basis of these in vitro findings, we evaluated the antitumor effects of bortezomib and RT in vivo. B88 cells were injected s.c. into the backs of nude mice and treatment was initiated when the tumor volume reached $50-100 \mathrm{~mm}^{3}$. As shown in Fig. 4B, the tumors treated with the combination of RT and bortezomib showed markedly less growth than the untreated controls, or the tumors treated with RT alone, or bortezomib alone. 

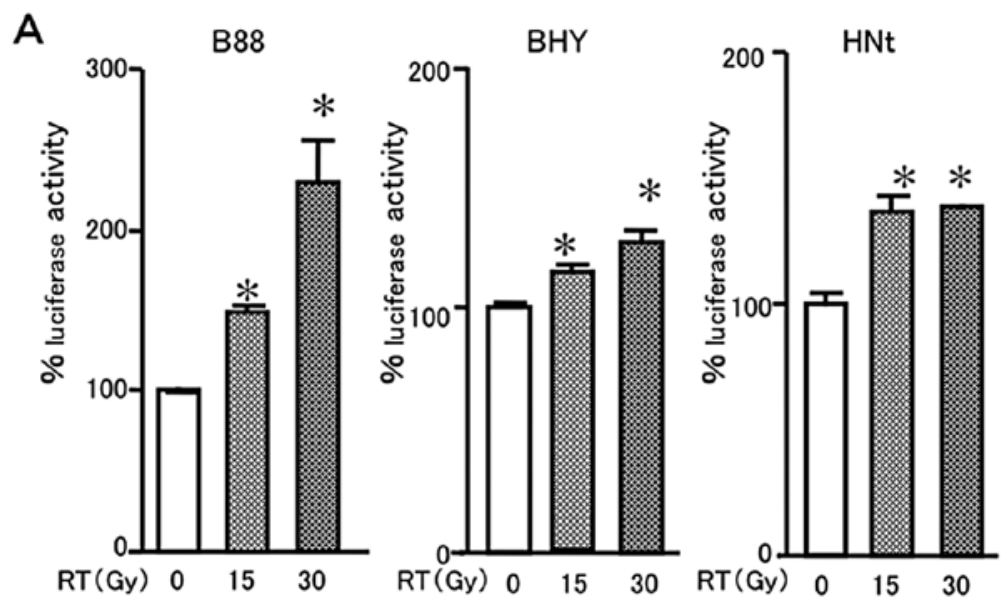

B

C

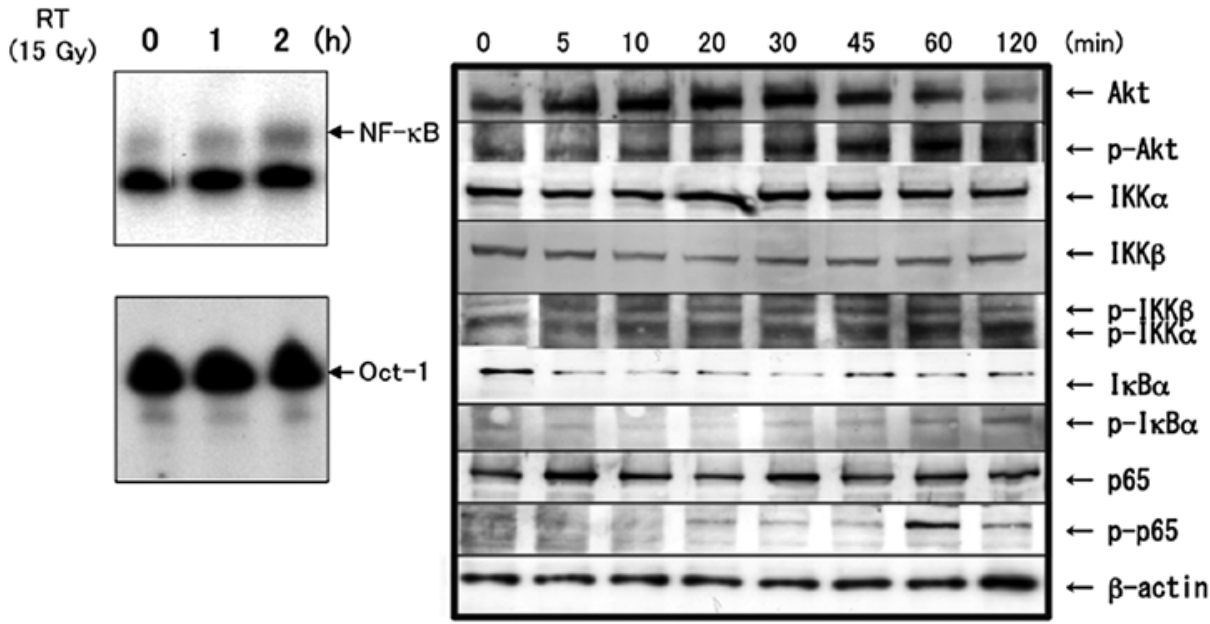

Figure 2. (A) Effects of RT on NF-kB activity in B88-luc, BHY-luc and HNt-luc cells investigated by luciferase assay. Cells were seeded in 6-well plates. After $24 \mathrm{~h}$, cells were treated with RT for $5 \mathrm{~h}$. The cells were then subjected to luciferase assay. NF- $\kappa \mathrm{B}$ activity was evaluated by luciferase assay as the percentage of luciferase activity. Results are representative of 3 experiments. ${ }^{*} \mathrm{p}<0.05$ versus untreated controls. (B) EMSA for NF- $\mathrm{kB}$ activation in B88 cells after treatment with or without RT $(15 \mathrm{~Gy})$. The specificity of the complex was confirmed by incubation with a 100 -fold excess of unlabeled $\mathrm{\kappa B}$ oligonucleotide. Oct-1 served as the loading control. (C) After the cells were exposed to RT, they were collected and lysed. The expression of Akt, IKK, IKB $\alpha$ and p65, phosphorylated Akt and $\mathrm{IKK} \alpha / \beta$ and the degradation and phosphorylation of I $\mathrm{K} B \alpha$ were examined by western blot analysis. $\beta$-actin served as the internal control.

Effects of bortezomib on $N F-\kappa B$ activity and the expression of IL-6, IL-8 and VEGF protein in tumor tissues. To examine whether or not bortezomib suppresses $\mathrm{NF}-\kappa \mathrm{B}$ activity in oral cancer tumor tissues, we investigated the $N F-\kappa B$ activity of B88-luc-bearing tumors in nude mice by luciferase assay. Our results showed that RT alone significantly increased the $\mathrm{NF}-\kappa \mathrm{B}$ activity compared with the untreated controls (Fig. 5A). Bortezomib significantly decreased the NF- $\kappa$ B activity induced by RT. Moreover, to clarify the mechanisms of the tumor growth inhibition by bortezomib, we investigated the effects of bortezomib and RT on the production of IL-6, IL-8 and VEGF in B88-bearing tumors in nude mice (Fig. 5B-D). Although bortezomib significantly decreased the production of IL-6, IL-8 and VEGF in the tumors from the nude mice, the production of these cytokines was markedly stimulated by RT. Bortezomib treatment followed by RT significantly suppressed the production of IL-6, IL-8 and VEGF as compared with RT exposure alone.
In order to determine whether bortezomib suppresses oral tumor growth by inhibiting tumor angiogenesis, we examined the microvessel density in oral cancer tissues in nude mice using immunohistochemical analysis of factor VIII (Fig. 5E). Treatment with bortezomib significantly reduced the microvessel density compared with the untreated controls or RT alone.

Effects of bortezomib on apoptosis and the expression of anti-apoptotic proteins induced by RT. Numerous apoptosis-related proteins, including cIAP1, cIAP2, XIAP and FLIP, all of which are regulated by $N F-\kappa B$, have been reported to be related to chemoresistance. To determine whether bortezomib mediates its effects by downregulating the expression of NF- $\kappa \mathrm{B}$-regulated proteins implicated in anti-apoptosis, we examined the effects of bortezomib and RT on the expression of cIAP1 and cIAP2 mRNA by quantitative RT-PCR. As shown in Fig. 6A and B, real-time RT-PCR revealed that cIAP1 and 
A

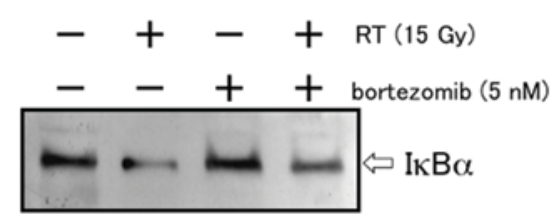

B
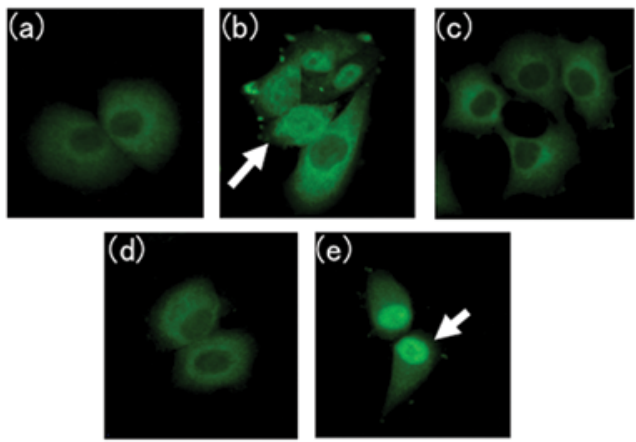

C
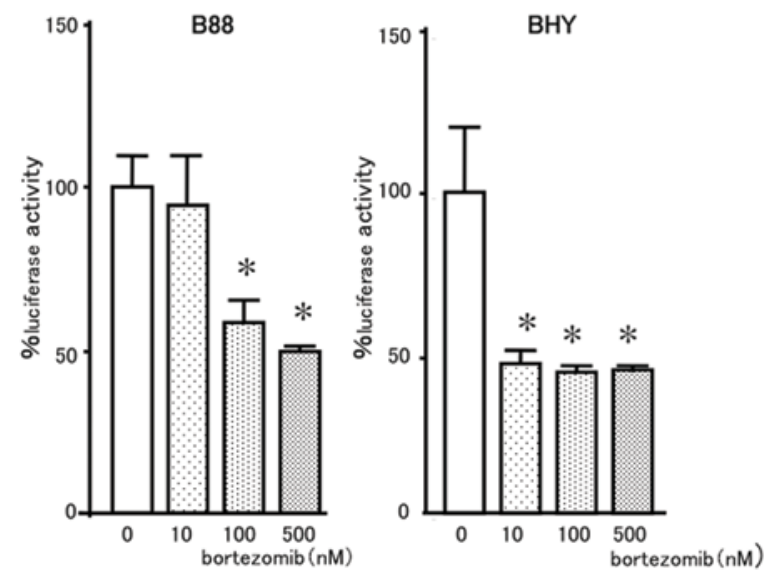

Figure 3. Bortezomib inhibited the activation of NF- $\mathrm{kB}$ induced by RT. (A) Western blot analysis of I $\kappa \mathrm{B} \alpha$ protein levels in B88 cells. B88 cells were treated with $5 \mathrm{nM}$ bortezomib and RT ( $15 \mathrm{~Gy})$. Whole cell fractions extracted from untreated cells and treated cells were subjected to SDS-PAGE. I $\mathrm{KB} \alpha$ protein was visualized with an IкB $\alpha$ specific antibody as described in Materials and methods. (B) Immunofluorescence staining of p65 protein in oral cancer cells. B88 cells were grown on coverslips in a $35-\mathrm{mm}$ dish. After the cells were exposed to RT (15 Gy) or treated with bortezomib, they were fixed in $4 \%$ paraformaldehyde and permeabilized with $0.1 \%$ Triton X-100. The expression of p65 protein was located in nuclei stimulated by RT. Arrows show the localization of p65 protein in the nuclei. (a) untreated, (b) RT (15 Gy), (c) bortezomib (5 nM) and RT (15 Gy), (d) bortezomib (5 nM) and (e) treatment with TNF- $\alpha$ as a positive control. (C) The effects of RT and bortezomib on NF- $\mathrm{BB}$ activity in B88-luc, BHY-luc and HNt-luc cells were investigated by luciferase assay. Cells were seeded in 6-well plates. After $24 \mathrm{~h}$, cells were treated with RT $(15 \mathrm{~Gy})$ and bortezomib for $5 \mathrm{~h}$. Then, cells were subjected to luciferase assay. $\mathrm{NF}-\mathrm{kB}$ activity was evaluated by luciferase assay as $100 \%$ luciferase activity on cells treated with RT only. Results are representative of 3 experiments. * $\mathrm{p}<0.05$ versus untreated controls.

cIAP2 mRNA expression was statistically increased by RT compared with the untreated controls, whereas bortezomib did not affect the expression levels of these 2 anti-apoptotic proteins. The combination of bortezomib and RT significantly reduced the cIAP1 and -2 mRNA expression levels as compared to RT alone. To investigate whether the enhanced cytotoxicity was due to apoptosis, the cleavage of PARP in cancer cells was examined by western blot analysis (Fig. 6C). The expression of cleaved PARP was significantly enhanced by the combined treatment with bortezomib and RT compared with either

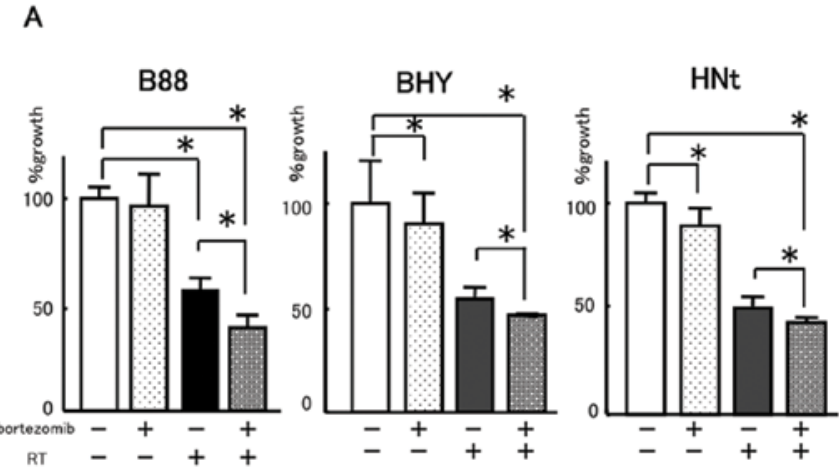

B

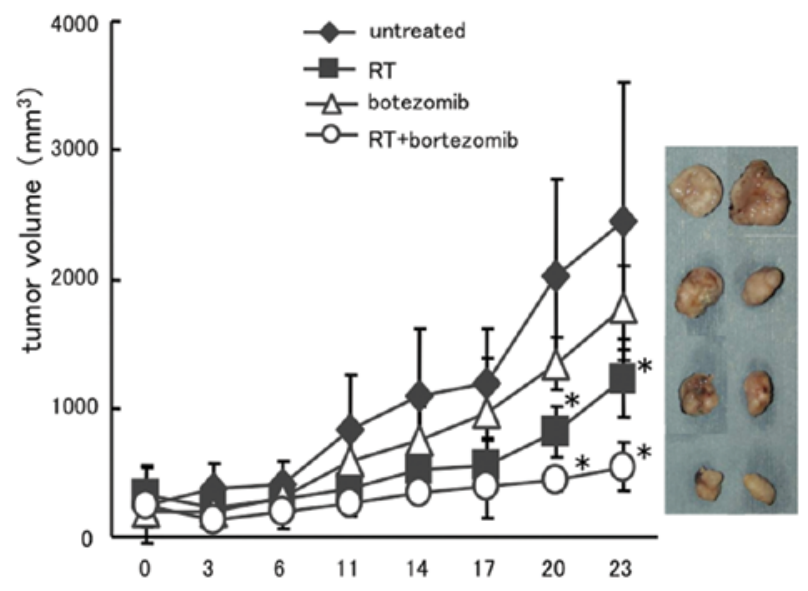

Figure 4. Effects of bortezomib and RT on tumor growth in vitro and in vivo. (A) Cells $\left(5 \times 10^{3}\right.$ cells/well) were seeded in 96-well plates. After $24 \mathrm{~h}$, cells were either treated with bortezomib (10 nM) or exposed to RT (7.5 Gy). Seventy-two hours later, in vitro cell growth was evaluated by MTT assay as the percentage of growth. ${ }^{*} \mathrm{p}<0.05$. (B) Role of bortezomib and $\mathrm{RT}$ in in vivo tumorigenicity of B88 cells. Cells $\left(5 \times 10^{6}\right)$ were inoculated into the backs of nude mice $(n=5)$. When the tumors reached $50-100 \mathrm{~mm}^{3}$ in volume, the mice were either treated with bortezomib $(0.1 \mathrm{mg} / \mathrm{kg} /$ day, i.v., 3 times/week) or exposed to RT (1.5 Gy/day, 3 times/week) for 2 weeks. Tumor diameters along 2 orthogonal axes were recorded and tumor volume was calculated by assuming a spherical shape of the tumor 3 times a week. Tumor volume was recorded as the mean volume for each treatment group $(n=5)$. Bars represent the mean \pm SD. ${ }^{*} p<0.05$ versus untreated controls. The images on the right represent the excised tumors.

bortezomib treatment or RT exposure alone. Furthermore, to identify the mechanism of tumor growth inhibition, we investigated the effects of bortezomib and RT on the expression of cIAP1, cIAP2, FLIP, XIAP, PARP and caspase-3 in B88 cancer tissues in nude mice (Fig. 6D). Our results showed that RT enhanced the expression of cIAP1, cIAP2, FLIP and XIAP; however, bortezomib downregulated the RT-induced expression of these proteins. Furthermore, the augmentation of the effect of bortezomib on RT-induced expression was considered to be cleaved PARP and the inhibition of the expression of caspase- 3 (Fig. 6D).

\section{Discussion}

In this study, we investigated whether or not bortezomib would be effective for the treatment of oral cancer. Our results showed that bortezomib significantly inhibited NF- $\kappa$ B activity and the proliferation of oral cancer cells both in vitro and 

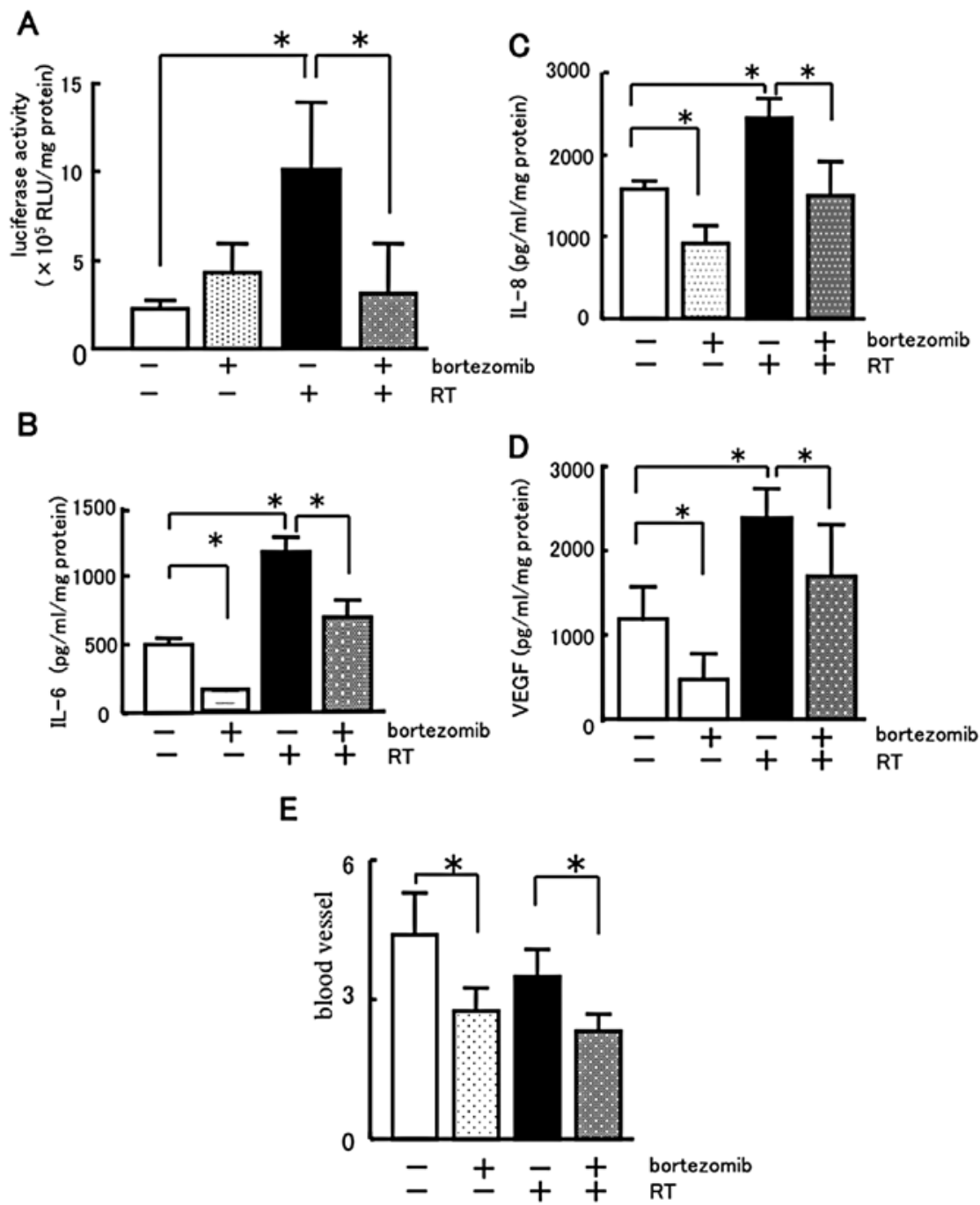

Figure 5. Effects of bortezomib on NF- $\kappa$ B activity, the expression of IL-6, IL-8 and VEGF protein and angiogenesis of tumor tissue. B88 or B88-luc cells $\left(5 x 10^{6}\right)$ were subcutaneously inoculated into the backs of nude mice. Tumor-bearing nude mice received either an i.v. administration of bortezomib $(0.1 \mathrm{mg} / \mathrm{kg} / \mathrm{day}$, 3 days), RT (1.5 Gy/day, 3 days), or a combination of bortezomib with RT. Twenty-four hours after the treatment, the tumors were excised and the protein was extracted. Samples were subjected to (A) luciferase assay for NF- $\kappa$ B activity and ELISA assay for (B) IL-6, (C) IL-8 and (D) VEGF protein. The excised tumors were fixed and applied to immunohistochemical staining of factor VIII. (E) The factor VIII-positive vessels in 5 microscopic fields of the highest vascular density were counted. ${ }^{*} \mathrm{p}<0.05$.

in vivo. The combined treatment of bortezomib and radiation suppressed $\mathrm{NF}-\kappa \mathrm{B}$ activity and tumor growth in vitro and in vivo as compared to radiation treatment alone. To investigate the mechanisms of tumor growth suppression by bortezomib, we examined the expression of $\mathrm{NF}-\kappa \mathrm{B}$ downstream signaling molecules, such as IL-6, VEGF, IL-8, cIAP1, cIAP2, XIAP and FLIP. The results showed that these molecules were significantly inhibited by treatment with bortezomib. Thus, our present study clearly demonstrates that bortezomib significantly inhibits tumor growth by the downregulation of NF- $\kappa \mathrm{B}$ and that the combined treatment with bortezomib and RT suppresses tumor growth when compared with radiation treatment alone. The mechanisms underlying the tumor growth inhibition by bortezomib were shown to be the suppression of angiogenesis via the inhibition of IL-8 and VEGF production, as well as the induction of apoptosis in cancer cells.

Several cultured human solid tumor cell lines demonstrate increased nuclear NF- $\mathrm{NB}$ activity and increased $\mathrm{NF}-\kappa \mathrm{B}$ transcriptional activity. NF- $\kappa \mathrm{B}$ activity is also activated in oral cancer, multiple myeloma, prostate, thyroid and breast cancer (17-22). We, as well as others, have previously shown that human oral cancer cells have a significantly enhanced NF- $\kappa \mathrm{B}$ activity compared to their normal counterparts, suggesting that $\mathrm{NF}-\kappa \mathrm{B}$ plays an important role in the development of oral cancer (14-17). It has been reported that enhanced $N F-\kappa B$ activity in many human solid tumors may be due to the augmentation of IKK activity (14). Increasing evidence indicates that the blockade of $\mathrm{NF}-\kappa \mathrm{B}$ pathways represents a particularly promising strategy for the development of novel and selective anticancer therapies (17-24). However, the possible mechanisms by which the suppression of $\mathrm{NF}-\kappa \mathrm{B}$ activity in cancer cells overcomes the resistance to conventional treatments, such as RT and chemotherapy, remain unknown. Thus, to better understand the mechanism by which $\mathrm{NF}-\kappa \mathrm{B}$ suppression enhances sensitivity to radio- and chemotherapy, we focused our attention on the effect of NF- $\mathrm{NB}$ inhibition on RT- and 5-FU-induced 
A

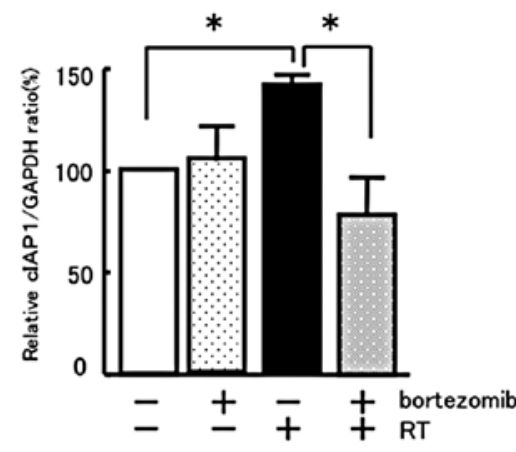

B

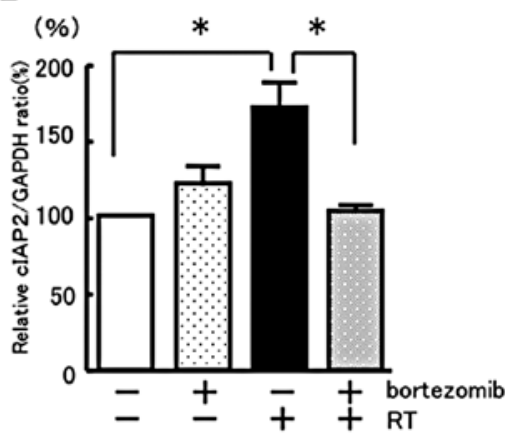

C

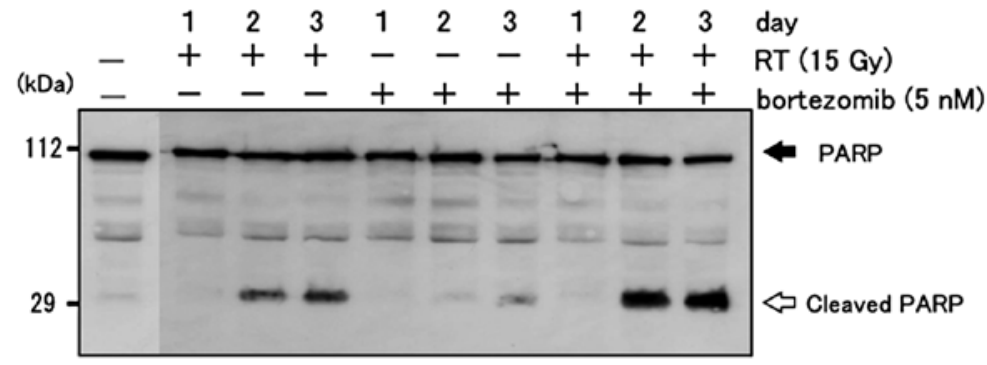

D

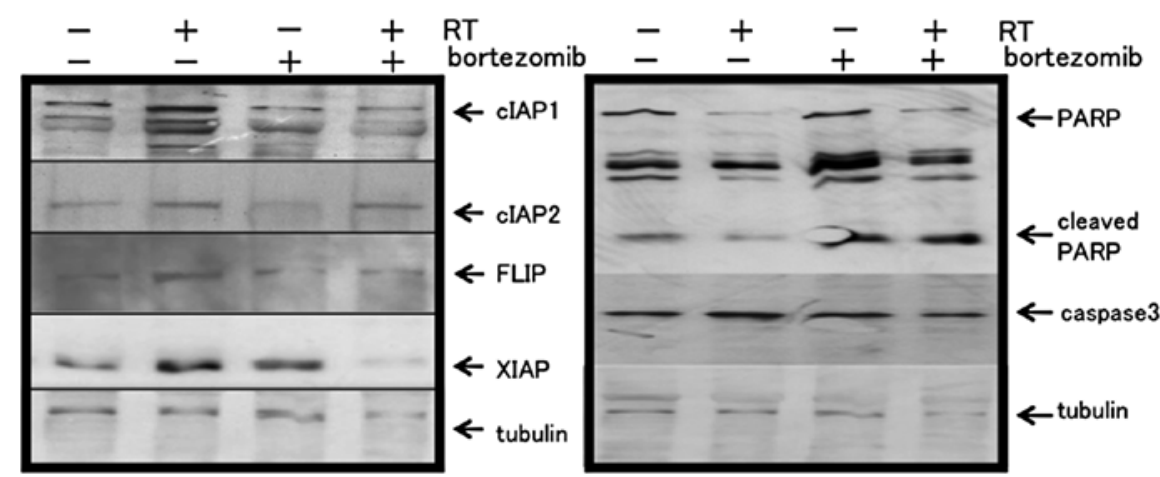

Figure 6. Effects of bortezomib on apoptosis and the expression of anti-apoptotic proteins induced by RT. Quantitative analysis of (A) cIAP1 and (B) cIAP2 mRNA transcription in B88 cells. RT-PCR products were quantitatively analyzed using an ABI 7000 sequence detection system. The data are shown as the ratio of the GAPDH-normalized fold change in the PCR product in bortezomib-treated or RT-exposed cells to the GAPDH-normalized amount of the PCR product in untreated cells. " $\mathrm{p}<0.05$. (C) Western blot analysis of PARP cleavage in cancer cells treated with either bortezomib (5 nM) or RT (15 Gy), or the combination with bortezomib and RT. Whole-cell fractions extracted from the cells were subjected to SDS-PAGE. The molecular weights of uncleaved and cleaved PARP were 112 and $29 \mathrm{kDa}$, respectively. (D) B88 cells $\left(5 \times 10^{6}\right)$ were subcutaneously inoculated into the backs of nude mice. Tumor-bearing nude mice received either an i.v. administration of bortezomib ( $0.1 \mathrm{mg} / \mathrm{kg} / \mathrm{day}, 3$ days), RT (1.5 Gy/day, 3 days), or a combination of bortezomib and RT. Twenty-four hours after the treatment, the tumors were excised and the protein was extracted. Samples were subjected to western blot analysis. The expression of cIAP1, cIAP2, FLIP, XIAP, caspase-3 and cleaved PARP was examined.

expression of IL-6 and IL-8 in human oral carcinoma cells, both of which contribute to tumor growth and angiogenesis and are regulated by NF- $\mathrm{\kappa B}(14,15)$. Our results showed that the consistent inhibition of NF- $\mathrm{kB}$ activity in human OSCC caused a marked reduction in tumorigenicity through the downregulation of IL-1 $\alpha$, IL-6, IL-8, VEGF and MMP-9, and that the NF-kB-suppressed B88 cells acquired sensitivity to radioand chemotherapy via the inhibition of RT- and 5-FU-induced production of IL-6 and IL-8 (16). Since it has previously been shown that several oral cancer cell lines, including B88 cells,

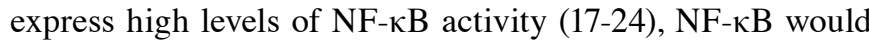
be an important therapeutic molecular target for improvement of conventional radio- and chemotherapy outcomes of patients with OSCC.
A number of methods have been reported as potential therapeutic strategies for targeting NF- $\mathrm{KB}$ in cancer treatment. Small interfering RNAs (siRNAs) (23) or decoy oligonucleotides blocking NF- $\mathrm{kB}$ protein synthesis (26) or DNA binding have been developed as experimental tools to examine the role of this factor in various models $(15,25)$. A number of studies have suggested that blocking the genes induced by $\mathrm{NF}-\kappa \mathrm{B}$ through these molecular approaches may have an antitumor effect in vivo. As novel anti-NF- $\mathrm{kB}$ agents, proteasome inhibitors (MG132, lactacystin, or bortezomib), ІкB $\alpha$ inhibitors (DHMEQ) and IKK inhibitors (PS-1145) have all been proposed $(17,19,28)$. Since bortezomib is the only drug currently under clinical development, we chose it for the investigation of its anticancer effects in this study. 
Although bortezomib significantly inhibited the NF- $\kappa \mathrm{B}$ activity in oral cancer cells, it did not suppress NF- $\kappa \mathrm{B}$ activity in the tumor tissues from nude mice (Fig. 5A). Arlt et al (40) reported that the autocrine mechanisms of IL-1 $\beta$ induced the constitutive activation of $\mathrm{NF}-\kappa \mathrm{B}$ and decreased the sensitivity for the proteasome inhibitor, MG132, in pancreatic cancer cells. It has also been found that the NF-kB inhibitory effects on the proteasome inhibitor were affected by the constitutive activation of NF- $\kappa \mathrm{B}$ in various tumors (41-43). As B88 cells do not have autocrine mechanisms of IL-1 $\beta$ or TNF- $\alpha$, an unknown mechanism in vivo disrupted the inhibitory effect of $\mathrm{NF}-\kappa \mathrm{B}$ activity by bortezomib.

Our data showed that RT induced the activity of NF- $\mathrm{NB}$ through the PI3K/AKT-IKK pathway, which led to the phosphorylation and degradation of $\mathrm{I} \kappa \mathrm{B} \alpha$. Bortezomib inhibits RT-induced NF- $\mathrm{NB}$ activation by suppressing the degradation of I $\kappa \mathrm{B} \alpha$, thus leading to enhanced radisosensitivity and increased apoptosis. Previously, it has been reported that $\mathrm{NF}-\kappa \mathrm{B}$ modulates the pathway of apoptotic responses induced by RT (44-46). RT causes many types of DNA damage, including DNA double-strand breaks (DSBs). Such DSBs are recognized by sensor proteins, which then bind to the damaged region and transduce a damaged signal to the components, ataxia telangiectasia mutated (ATM). ATM phosphorylates serine-85 of the NF- $\kappa \mathrm{B}$ essential modulator (NEMO) to promote its ubiquitin-dependent nuclear export and is also exported in a NEMO-dependent manner to the cytoplasm, where it associates with and causes the activation of IKK. Thus, the regulated nuclear shuttling of NEMO is linked to 2 signaling kinases, ATM and IKK.

Although RT has been used as an effective anticancer modality for the pre- and post-operative treatment of oral cancer, it has been demonstrated that RT stimulates the production of angiogenic factors; VEGF expression was induced in Lewis lung carcinomas in vitro and in vivo after exposure to RT (47-49). In addition, the autocrine production of IL- 6 by cancer cells and the inducible production of VEGF and IL- 8 by RT and chemotherapeutic agents are considered to be the mechanisms whereby cancer cells acquire resistance to radiotherapy $(50,51)$. On the basis of these findings, Gorski et al (49) and De Larco et al (50) suggested that the inhibition of these molecules by means of an antagonistic action using a neutralizing antibody or an angiogenesis inhibitor (angiostatin) would increase the antitumor effects of RT. Karashima et al (6) reported that NF- $\kappa$ B mediated angiogenesis and the metastasis of human bladder cancer cells through the regulation of IL-8. Huang et al (39) showed that the blockade of $\mathrm{NF}-\kappa \mathrm{B}$ signaling inhibited angiogenesis and the tumorigenicity of human ovarian cancer cells by suppressing the expression of VEGF and IL-8. In MDA-MB-231 breast cancer cells, it has been reported that MG132 inhibited the angiogenesis and the expression of VEGF mRNA through the suppression of $\mathrm{NF}-\kappa \mathrm{B}$ activity (39). A novel finding of the present study was that bortezomib inhibited tumor growth via the suppression of angiogenesis through the inhibition of RT induced production of IL-8 and VEGF in oral cancer cells.

Although RT induces cell death via the apoptotic pathway, the induction of $\mathrm{NF}-\kappa \mathrm{B}$ protects cancer cells from RT-induced apoptosis and regulates the anti-apoptotic protein. On the other hand, we found that an another possible mechanism of the effects of bortezomib on the inhibition of tumor growth was responsible for the suppression of cIAP1, cIAP2, FLIP and XIAP. However, it has been shown that $\mathrm{NF}-\kappa \mathrm{B}$ regulates the many signaling pathways related to cell death, including the reactive oxygen species (ROS) pathway and c-Jun N-terminal kinase (JNK) pathway, but not the caspase pathway (52-54). In future studies, therefore, we aim to analyze the effects of bortezomib or RT on these signaling pathways.

In conclusion, the present study clearly demonstrates that bortezomib significantly inhibits tumor growth and that the combined treatment with bortezomib and RT inhibits tumor growth as compared to radiation treatment alone. The mechanisms underlying the tumor growth inhibitory effects of bortezomib include the suppression of angiogenesis via the inhibition of IL-8 and VEGF production, as well as the induction of apoptosis in cancer cells. A novel molecular targeting therapy using the proteasome inhibitor, bortezomib, to inhibit $\mathrm{NF}-\kappa \mathrm{B}$ may be effective in the treatment of oral cancer.

\section{Acknowledgements}

This work was supported in part by Grants-in-Aid for Scientific research (C) (24593036).

\section{References}

1. Sen R and Baltimore D: Multiple nuclear factors interact with the immunoglobulin enhancer sequences. Cell 46: 705-716, 1986.

2. Baeuerle PA and Baltimore D: NF-kappa B: ten years after. Cell 87: 13-20, 1996.

3. Yamamoto $\mathrm{Y}$ and Gaynor RB: IкB kinases: key regulators of the NF-кB pathway. Trends Biochem Sci 29: 72-79, 2004.

4. Van Antwerp DJ, Martin SJ, Kafri T, Green DR and Verma IM: Suppression of TNF-alpha-induced apoptosis by $\mathrm{NF}-\kappa \mathrm{B}$. Science 274: 787-789, 1996.

5. Traenckner EB, Pahl HL, Henkel T, Schmidt KN, Wilk S and Baeuerle PA: Phosphorylation of human IkappaB-alpha on serines 32 and 36 controls Ikappa B-alpha proteolysis and NF-kappa B activation in response to diverse stimuli. EMBO J 14: 2876-2883, 1995.

6. Karashima T, Sweeney P, Kamat A, et al: Nuclear factor- $\kappa \mathrm{B}$ mediates angiogenesis and metastasis of human bladder cancer through regulation of interleukin-8. Clin Cancer Res 9: 2786-2797, 2003.

7. Dhawan P, Singh AB, Ellis DL and Richmond A: Constitutive activation of Akt/Protein kinase $B$ in melanoma leads to up-regulation of nuclear factor- $\kappa \mathrm{B}$ and tumor progression. Cancer Res 62: 7335-7342, 2002.

8. Sato H and Seiki M: Regulatory mechanism of $92 \mathrm{kDa}$ type IV collagenase gene expression which is associated with invasiveness of tumor cells. Oncogene 8: 395-405, 1993.

9. Wang CY, Mayo MW, Korneluk RG, Goeddel DV and Baldwin AS Jr: NF- $\kappa$ B antiapoptosis: induction of TRAF1 and TRAF2 and c-IAP1 and c-IAP2 to suppress caspase- 8 activation. Science 281: 1680-1683, 1998.

10. Wang CY, Cusack JC Jr, Liu R and Baldwin AS Jr: Control of inducible chemoresistance: enhanced anti-tumor therapy through increased apoptosis by inhibition of NF- $\kappa$ B. Nat Med 5: 412-417, 1999.

11. Hideshima T, Chauhan D, Richardson $\mathrm{P}$, et al: $\mathrm{NF}-\kappa \mathrm{B}$ as a therapeutic target in multiple myeloma. J Biol Chem 277: 16639-16647, 2002.

12. Denlinger CE, Rundall BK and Jones DR: Modulation of antiapoptotic cell signaling pathways in non-small cell lung cancer: the role of NF-кB. Semin Thorac Cardiovasc Surg 16: 28-39, 2004.

13. Smith CW, Chen Z, Dong G, et al: The host environment promotes the development of primary and metastatic squamous cell carcinomas that constitutively express proinflammatory cytokines IL-1 $\alpha$, IL-6, GM-CSF and KC. Clin Exp Metastasis 16: 655-664, 1998. 
14. Tamatani T, Azuma M, Aota K, Yamashita T, Bando T and Sato M: Enhanced IאB kinase activity is responsible for the augmented activity of NF- $\mathrm{B}$ in human head and neck carcinoma cells. Cancer Lett 171: 165-172, 2001.

15. Tamatani T, Azuma M, Ashida Y, et al: Enhanced radiosensitization and chemosensitization in NF- $\mathrm{\kappa B}$ suppressed human oral cancer cells via the inhibition of $\gamma$-irradiation- and 5-FU-induced production of IL-6 and IL-8. Int J Cancer 108: 912-921, 2004.

16. Visconti R, Cerutti J, Battista S, et al: Expression of the neoplastic phenotype by human thyroid carcinoma cell lines requires NF-кB p65 protein expression. Oncogene 15: 1987-1994, 1997.

17. Sartore-Bianchi FA, Gasparri F, Galvani A, et al: Bortezomib inhibits nuclear factor- $\kappa \mathrm{B}$-dependent survival and has potent in vivo activity in mesothelioma. Clin Cancer Res 13: 5942-5951, 2007.

18. Canfield SE, Zhu K, Williams SA and McConkey DJ: Bortezomib inhibits docetaxel-induced apoptosis via a p21-dependent mechanism in human prostate cancer cells. Mol Cancer Ther 5: 2043-2050, 2006.

19. Bazzaro M,Lee MK,Zoso A, et al: Ubiquitin-proteasome system stress sensitizes ovarian cancer to proteasome inhibitor-induced apoptosis. Cancer Res 66: 3754-3763, 2006.

20. An J, Sun YP, Adams J, Fisher M, Belldegrun A and Rettig MB: Drug interactions between the proteasome inhibitor bortezomib and cytotoxic chemotherapy, tumor necrosis factor (TNF) o and TNF-related apoptosis-inducing ligand in prostate cancer. Clin Cancer Res 9: 4537-4545, 2003.

21. Aggarwal BB, Shishodia S, Takada Y, Banerjee S, Newman RA, Bueso-Ramos CE and Price JE: Curcumin suppresses the paclitaxel-induced nuclear factor- $\kappa \mathrm{B}$ pathway in breast cancer cells and inhibits lung metastasis of human breast cancer in nude mice. Clin Cancer Res 11: 7490-7498, 2005.

22. Olivier S, Robe $\mathrm{P}$ and Bours V: Can NF- $\kappa \mathrm{B}$ be a target for novel and efficient anti-cancer agents? Biochem Pharmacol 72: 1054-1068, 2006.

23. Kashkar H, Deggerich A, Seeger JM, Yazdanpanah B, Wiegmann K, Haubert D, Pongratz $C$ and Krönke $M$ : NF- $\mathrm{B}$-independent down-regulation of XIAP by bortezomib sensitizes HL B cells against cytotoxic drugs. Blood 109: 3982-3988, 2007.

24. Adams J, Palombella VJ, Sausville EA, et al: Proteasome inhibitors: A novel class of potent and effective antitumor agents. Cancer Res 59: 2615-2622, 1999.

25. Duffey DC, Chen Z, Dong G, et al: Expression of a dominant-negative mutant inhibitor- $\kappa \mathrm{B} \alpha$ of nuclear factor- $\kappa \mathrm{B}$ in human head and neck squamous cell carcinoma inhibits survival, proinflammatory cytokine expression and tumor growth in vivo Cancer Res 59: 3468-3474, 1999.

26. Tomita T, Takeuchi E, Tomita N, et al: Suppressed severity of collagen-induced arthritis by in vivo transfection of nuclear factor $\kappa \mathrm{B}$ decoy oligodeoxynucleotides as a gene therapy. Arthritis Rheum 42: 2532-2542, 1999.

27. Kim IA, Bae SS, Fernandes A, et al: Selective inhibition of Ras, phosphoinositide 3 kinase and Akt isoforms increases the radiosensitivity of human carcinoma cell lines. Cancer Res 65: 7902-7910, 2005.

28. Matsumoto G, Namekawa J, Muta M, et al: Targeting of nuclear factor $\kappa \mathrm{B}$ pathways by dehydroxymethylepoxyquinomicin, a novel inhibitor of breast carcinomas: antitumor and antiangiogenic potential in vivo. Clin Cancer Res 11: 1287-1293, 2005

29. Messersmith WA, Baker SD, Lassiter L, et al: Phase I trial of bortezomib in combination with docetaxel in patients with advanced solid tumors. Clin Cancer Res 12: 1270-1275, 2006.

30. Cataldi A, Rapino M, Centurione L, et al: NF- $\kappa \mathrm{B}$ activation plays an antiapoptotic role in human leukemic K562 cells exposed to ionizing radiation. J Cell Biochem 89: 956-963, 2003.

31. Loercher A, Lee TL, Ricker JL, et al: Nuclear factor- $\kappa \mathrm{B}$ is an important modulator of the altered gene expression profile and malignant phenotype in squamous cell carcinoma. Cancer Res 64: 6511-6523, 2004.

32. Van Waes C, Chang AA, Lebowitz PF, et al: Inhibition of nuclear factor- $\kappa \mathrm{B}$ and target genes during combined therapy with proteasome inhibitor bortezomib and reirradiation in patients with recurrent head-and-neck squamous cell carcinoma. Int J Radiat Oncol Biol Phys 63: 1400-1412, 2005.

33. Nakagawa K, Tamura T, Negoro S, et al: Phase I pharmacokinetic trial of the selective oral epidermal growth factor receptor tyrosine kinase inhibitor gefitinib ('Iressa', ZD1839) in Japanese patients with solid malignant tumors. Ann Oncol 14: 922-930, 2003 .
34. Tan C and Waldmann TA: Proteasome inhibitor PS-341, a potential therapeutic agent for adult T-cell leukemia. Cancer Res 62: 1083-1086, 2002.

35. Scaife CL, Kuang J, Wills JC, et al: Nuclear factor $\kappa B$ inhibitors induce adhesion-dependent colon cancer apoptosis: implications for metastasis. Cancer Res 62: 6870-6878, 2002.

36. LeBlanc R, Catley LP, Hideshima T, et al. Proteasome inhibitor PS-341 inhibits human myeloma cell growth in vivo and prolongs survival in a murine model. Cancer Res 62: 4996-5000, 2002.

37. Amiri KI, Horton LW, LaFleur BJ, Sosman JA and Richmond A: Augmenting chemosensitivity of malignant melanoma tumors via proteasome inhibition: implication for bortezomib (VELCADE, PS-341) as a therapeutic agent for malignant melanoma. Cancer Res 64: 4912-4918, 2004

38. Rahman KM and Sarkar FH: Inhibition of nuclear translocation of nuclear factor- $\kappa \mathrm{B}$ contributes to 3,3'-diindolylmethane-induced apoptosis in breast cancer cells. Cancer Res 65: 364-371, 2005

39. Huang S, Robinson JB, Deguzman A, et al: Blockade of nuclear factor- $\kappa \mathrm{B}$ signaling inhibits angiogenesis and tumorigenicity of human ovarian cancer cells by suppressing expression of vascular endothelial growth factor and interleukin 8. Cancer Res 60: 5334-5339, 2000

40. Arlt A, Vorndamm J, Müerköster S, et al: Autocrine production of interleukin $1 \beta$ confers constitutive nuclear factor $\mathrm{\kappa B}$ activity and chemoresistance in pancreatic carcinoma cell lines. Cancer Res 62: 910-916, 2002

41. Yang $\mathrm{J}$ and Richmond A: Constitutive $\mathrm{I} \kappa \mathrm{B}$ kinase activity correlates with nuclear factor- $\mathrm{kB}$ activation in human melanoma cells Cancer Res 61: 4901-4909, 2001.

42. Kothny-Wilkes G, Kulms D, Luger TA, et al: Interleukin-1 protects transformed keratinocytes from tumor necrosis factorrelated apoptosis-inducing ligand- and CD95-induced apoptosis but not from ultraviolet radiation-induced apoptosis. J Biol Chem 274: 28916-28921, 1999.

43. Vale T, Ngo TT, White MA and Lipsky PE: Raf-induced transformation requires an interleukin 1 autocrine loop. Cancer Res 61: 602-607, 2001.

44. Huang TT, Wuerzberqer-Davis SM, Wu ZH, et al: Sequential modification of NEMO/IKK $\gamma$ by SUMO- 1 and ubiquitin mediates NF- $\kappa \mathrm{B}$ activation by genotoxic stress. Cell 115 : $565-576,2003$

45. Mabb AM, Wuerzberqer-Davis SM and Miyamoto S: PIASy mediates NEMO sumoylation and NF- $\mathrm{BB}$ activation in response to genotoxic stress. Nat Cell Biol 8: 986-993, 2006.

46. Janssens S and Tschopp J: Signals from within: the DNA-damageinduced NF- $\kappa$ B response. Cell Death Differ 13: 773-784, 2006.

47. Munshi A, Kurland JF, Nishikawa T, et al: Inhibition of constitutively activated nuclear factor- $\kappa \mathrm{B}$ radiosensitizes human melanoma cells. Mol Cancer Ther 3: 985-992, 2004.

48. Shumway SD and Miyamoto S: A mechanistic insight into a proteasome-independent constitutive inhibitor $\kappa \mathrm{B} \alpha(\mathrm{I} \kappa \mathrm{B} \alpha)$ degradation and nuclear factor $\kappa \mathrm{B}(\mathrm{NF}-\kappa \mathrm{B})$ activation pathway in WEHI-231 B-cells. Biochem J 380: 173-180, 2004.

49. Gorski DH, Beckett MA, Jaskowiak NT, et al: Blockade of the vascular endothelial growth factor stress response increases the antitumor effects of ionizing radiation. Cancer Res 59: 3374-3378, 1999.

50. De Larco JE, Wuertz BR, Manivel JC and Furcht LT: Progression and enhancement of metastatic potential after exposure of tumor cells to chemotherapeutic agents. Cancer Res 61: 2857-2861, 2001.

51. Conze D, Weiss L, Regen PS, et al: Autocrine production of interleukin 6 causes multidrug resistance in breast cancer cells. Cancer Res 61: 8851-8858, 2001.

52. Tang G, Minemoto Y, Dibling B, et al: Inhibition of JNK activation through NF- $\mathrm{B}$ target genes. Nature 414: 313-317, 2001.

53. Yu C, Friday BB, Lai JP, Yang L, et al: Cytotoxic synergy between the multikinase inhibitor sorafenib and the proteasome inhibitor bortezomib in vitro: induction of apoptosis through Akt and c-Jun NH2-terminal kinase pathways. Mol Cancer Ther 5: 2378-2387, 2006.

54. Rumpold H, Salvador C, Wolf AM, Tilg H, Gastl G and Wolf D: Knockdown of PgP resensitizes leukemic cells to proteasome inhibitors. Biochem Biophys Res Commun 361: 549-554, 2007. 